\title{
Characteristics of Y-Jet-Type Airblast Atomizer with Self-Control Function*
}

\author{
Masatoshi DAIKOKU ${ }^{* *}$, Hitoshi FURUDATE** and Takao INAMURA ${ }^{* * *}$
}

\begin{abstract}
A new type of Y-jet airblast atomizer was developed to control mean droplet diameter over a wide range of liquid flow rates. This atomizer employs a fluid amplifier system that controls the liquid delivery to two kinds of injection ports having different inner diameters. In order to clarify the effect of amplifier dimensions on spray characteristics, the relationship between flow rate characteristics and spray characteristics was investigated and flow visualization of the flow inside the fluid amplifier was performed. When the main flow rates were $3.0 \mathrm{~g} / \mathrm{s}$ and $4.0 \mathrm{~g} / \mathrm{s}$, the flow rate characteristics of the amplifier were improved, and good spray characteristics were obtained.
\end{abstract}

Key Words: Atomization, Fuel Injection, Combustion, Fluid Amplifier, Y-Jet Atomizer, Spray Characteristics, Automatic Control

\section{Introduction}

In order to control the spray characteristics (the mean diameter of the spray) of a Y-jet airblast atomizer, an attempt was made to incorporate a fluid amplifier system ${ }^{(1)}$ into the atomizer. By dividing the liquid flow into two kinds of injection ports having different inner diameters ${ }^{(2)}$, the overall mean diameter of the spray was maintained at a fixed value over a broad liquid flow rate. Although this strategy was useful in order to suppress a change in the mean diameter due to the increase in the liquid flow rate in low-flow-rate regions, there was an increase in the mean diameter of the spray, probably due to an inadequate division of liquid flow to the ports in the high-flow-rate region. In order to improve this result, we examined the influence of larger port dimensions on the overall mean diameter of the spray, and determined a port capable of controlling the mean diameter to a fixed value that is capable of suppressing an increase in diameter in large-flow-rate regions ${ }^{(3)}$. Furthermore, in order to improve the spray characteristics, we examined the effect of fluid amplifier splitter specifications on the mean diameter of the spray ${ }^{(4),(5)}$, and confirmed that it is possible to maintain the mean diameter of

* Received 25th February, 2004 (No. 04-4063)

** Department of Mechanical System on Information Technology, Hachinohe Institute of Technology, 88-1 Myo Ohbiraki, Hacinohe-shi, Aomori 031-8501, Japan.

E-mail: daikoku@hi-tech.ac.jp

*** Faculty of Science and Technology, Hirosaki University, 3 Bunkyo-cho, Hirosaki-shi, Aomori 036-8561, Japan. E-mail: tina@cc.hirosaki-u.ac.jp the spray approximately constant, provided that appropriate fluid amplifier offset values are employed. However, the effects of the dimensions of the fluid amplifier on the flow rate division to the ports and on the spray characteristics remain unclear.

The objective of the present study is to develop a Y-jet type airblast atomizer capable of producing a fixed mean diameter over a broad flow rate range. In order to attain further improvements in the spray characteristics of the Yjet type airblast atomizer, we seek herein to achieve favorable atomization through a detailed review of the functions of both the main flow and the control flow in the fluid amplifier system, which plays a critical role in determining how the liquid flow rate is divided.

\section{Experimental Apparatus and Method}

\subsection{Structure of the atomizer}

Figure 1 shows the structure of the multi-port Yjet type airblast atomizer incorporating a fluid amplifier system. The liquid passes through the first- (No. 1) and second-stage (No. 2) fluid amplifiers and through a thirdstage (No. 3) orifice, and is then atomized by high-speed air. The atomizer tip has eight smaller ports (SPs) and four larger ports (LPs) having inner diameters of $1.4 \mathrm{~mm}$ and $2.4 \mathrm{~mm}$, respectively. Since the atomizing air velocity in the LPs is lower than that in the SPs, relatively coarse droplets will be discharged from the LPs.

\subsection{Structure of the fluid amplifier}

Figure 2 shows the structures of the fluid amplifier and the orifice that are incorporated into the atomizer. The fluid amplifier flow path is comprised of a $1 \mathrm{~mm}$-deep 
groove engraved onto a 4-mm-thick disc. The two fluid amplifiers have two flow paths: the main nozzle and a control port through which the control stream flows. The two flow paths are divided by a splitter (the sharp-edged section in the figure). Figure 2 (c) shows an orifice ${ }^{(2)}$ that prevents any adverse impact on the flow rate control by the negative pressure that is generated in the port.

Figure 3 shows a systematic diagram of the liquid flow in the fluid amplifier system. The supplied liquid is divided by the fluid amplifier system. Finally, the liquid is
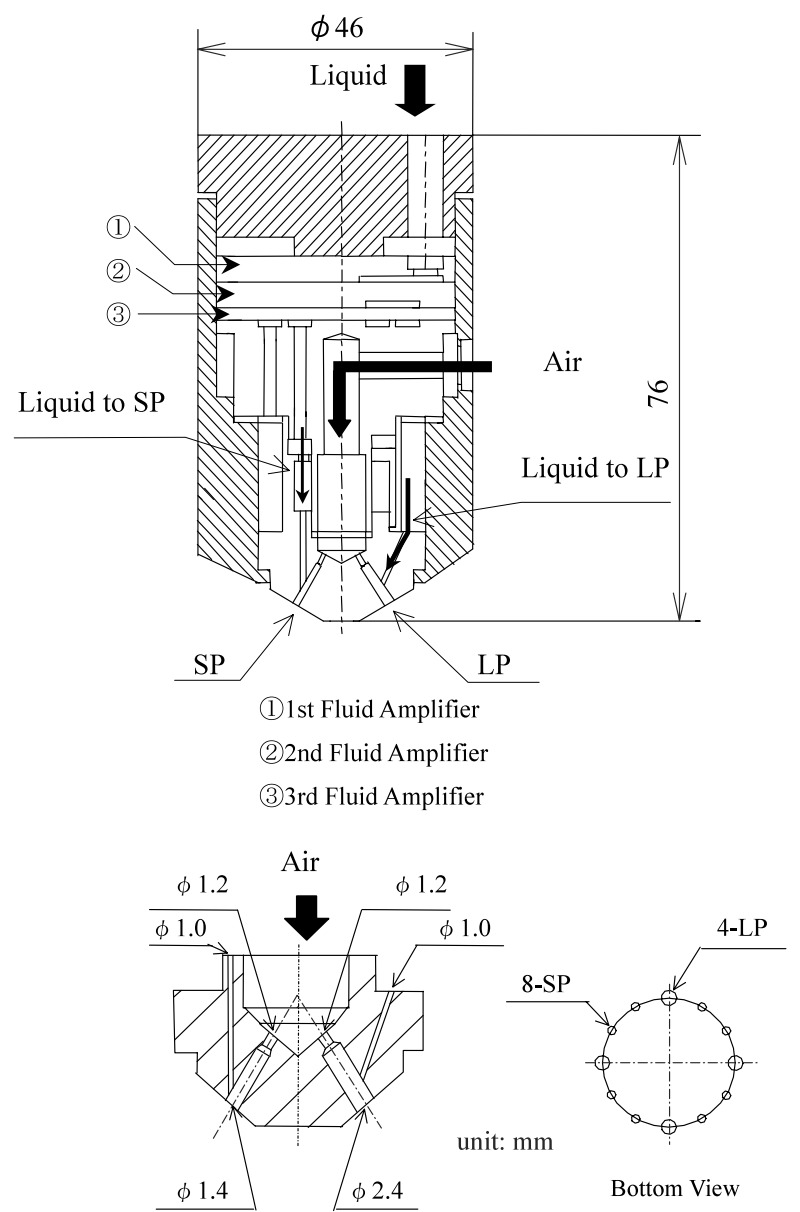

Fig. 1 Y-jet-type twin fluid atomizer supplied to the LPs and SPs in the atomizer tip.

\subsection{Fluid amplifier specifications}

The fluid amplifier system that is incorporated into the atomizer has a structure such that in the first stage (Fig. 2(a)), the liquid from one inlet is flowed into the main nozzle and the control port. Therefore, the rates of the main and control flows cannot be regulated individually. In view of this fact, we consider the splitter offset at the first-stage fluid amplifier to be a critical parameter for the determination of the flow rates for the main and control flows. Similarly, the second-stage fluid amplifier is also considered to be important for the determination of the flow rates into the SPs and LPs corresponding to the flow from the first stage.

Figure 4 (a) and (b) illustrate the splitter section of the fluid amplifier (corresponding to Fig. 2 (a) and (b)). The offset into the control flow inlet is represented as a negative value $(-)$, and that into the main flow is represented as a positive value $(+)$. The present paper focuses on a fluid amplifier system that incorporates a combination of the first-stage offset $(-0.5 \mathrm{~mm})$, the second-stage offset $(0.6 \mathrm{~mm})$ and the third-stage orifice diameter $(1 \mathrm{~mm})$ which produced favorable atomization characteristics in a previous paper ${ }^{(4)}$.

In order to clarify the fluid amplifier system characteristics, we constructed a new fluid amplifier of transparent acryl resin plate having the structure shown in Fig. 5. The new fluid amplifier is not incorporated into the atomizer and is intended for the investigation of both the flow rate characteristics and the inside flow pattern with no at-

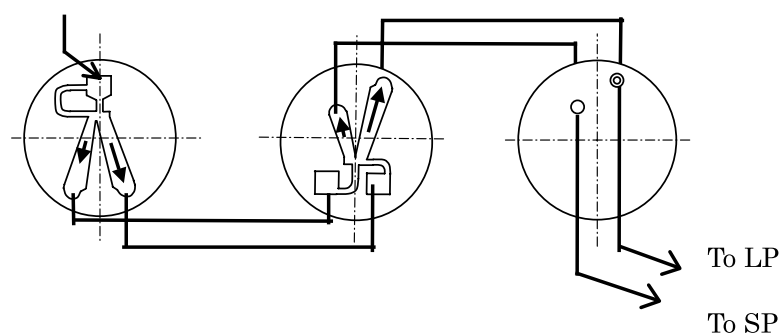

Fig. 3 Combination of three fluid amplifiers

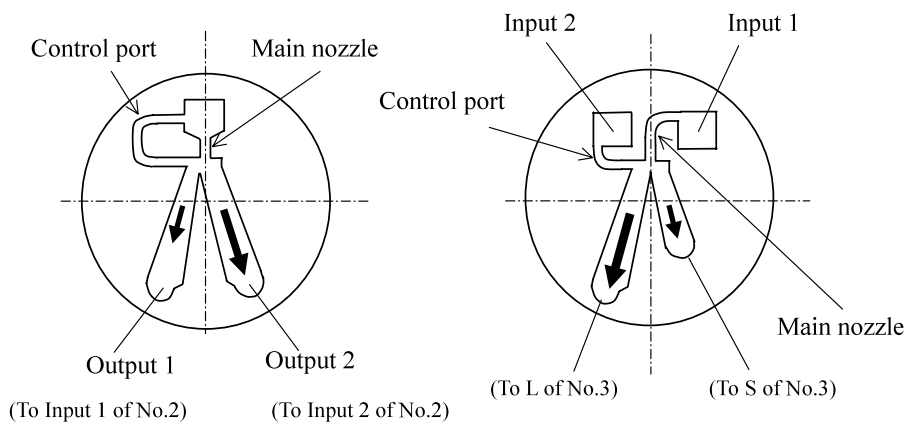

(a) 1st fluid amplifier (No. 1) (b) 2nd fluid amplifier (No. 2)

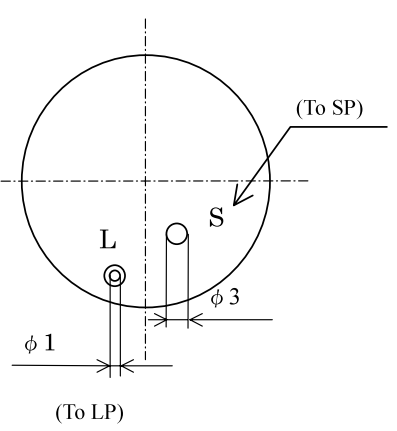

(c) Orifice plate (No. 3)

Fig. 2 Details of fluid amplifier system 


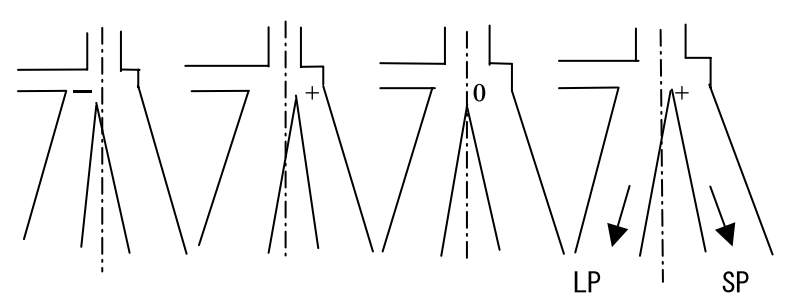

(a) 1st fluid amplifier

(b) 2nd fluid amplifier

Fig. 4 The splitter offsets of the first and the second amplifiers

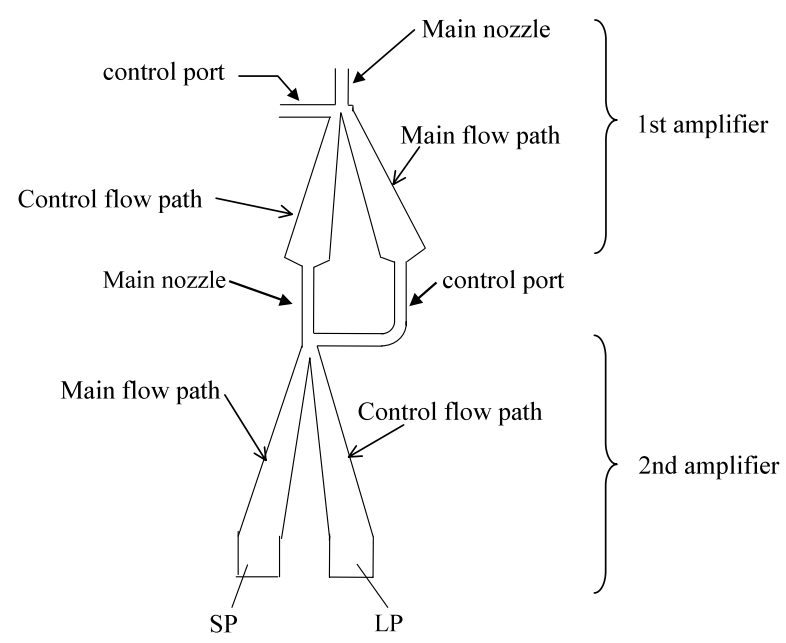

Fig. 5 Fluid amplifier for flow observation

omizing air. The structure permits liquid to be supplied both from the main nozzle and from the control port of the first-stage amplifier.

\subsection{Experimental procedure}

The liquid used in the experiments was tap water. The experiments were conducted using a liquid flow rate $\left(m_{\mathrm{L}}\right)$ range of $3.95-11.9 \mathrm{~g} / \mathrm{s}$ and an atomizing air flow rate $\left(m_{\mathrm{A}}\right)$ of $4.0-8.0 \mathrm{~g} / \mathrm{s}$.

A PDPA with a transmitter-receiver focal distance of $250 \mathrm{~mm}$ was used for determining mean diameters. Measurements were performed under a condition of forward scattering. The Sauter mean diameter (SMD) was determined in the plane approximately $100 \mathrm{~mm}$ below the atomizer by measuring the quantities $S M D_{\mathrm{s}}$ and $S M D_{1}$ at the center of the spray discharged from the SP and the LP, respectively. The $S M D_{\mathrm{s}}$ and $S M D_{\mathrm{l}}$ were determined from at least 3 such measurements, respectively, and the difference between the measured and the averaged values was approximately $\pm 5 \%$. The total $S M D_{\mathrm{t}}$ for the overall spray was calculated according to the following equation ${ }^{(2)}$ using the flow rates $\left(m_{\mathrm{Ls}}, m_{\mathrm{Ll}}\right)$ into the ports:

$$
S M D_{\mathrm{t}}=\frac{m_{\mathrm{L}}}{\frac{m_{\mathrm{Ls}}}{S M D_{\mathrm{s}}}+\frac{m_{\mathrm{Ll}}}{S M D_{\mathrm{l}}}}
$$

where

$$
m_{\mathrm{L}}=m_{\mathrm{Ls}}+m_{\mathrm{Ll}}
$$

The flow rate $m_{\mathrm{Ll}}$ from the LP was measured at all four LPs using an isokinetic sampling probe, and the $m_{\mathrm{Ls}}$

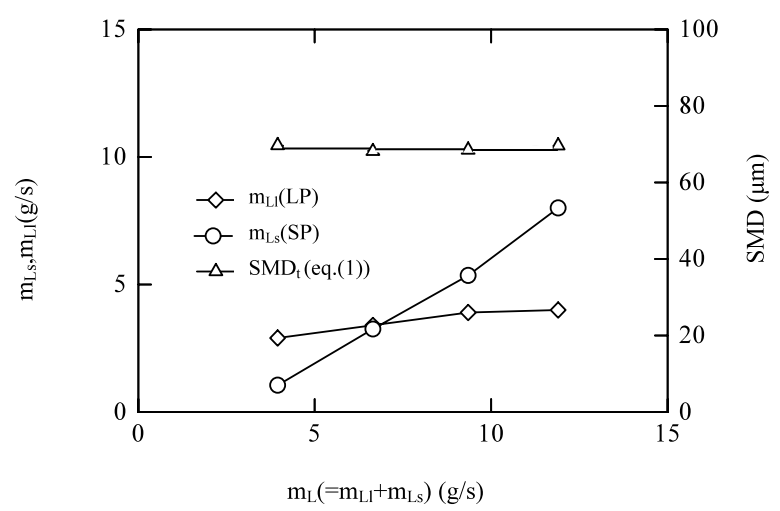

Fig. 6 Effects of total liquid flow rate on liquid division and $S M D$ for $m_{\mathrm{A}}=6.0 \mathrm{~g} / \mathrm{s}$ (Splitter offset of No. 1: $-0.5 \mathrm{~mm}$, No. 2: $0.6 \mathrm{~mm}$ )

was determined in terms of the difference from the total liquid flow rate $m_{\mathrm{L}}$ (Eq. (2)). The flow rate $m_{\mathrm{Ll}}$ was determined from at least 5 such measurements for each experimental condition, and the maximum deviation of the flow rate $m_{\mathrm{Ll}}$ and $m_{\mathrm{Ls}}$ were approximately $\pm 7 \%$ when compared with the averaged values.

\section{Results and Discussion}

\subsection{Atomization characteristics of the Y-jet air- blast atomizer incorporating the fluid ampli- fier system}

Figure 6 shows an example in which a change in liquid flow rates $m_{\mathrm{Ls}}$ and $m_{\mathrm{Ll}}$ from the SP and the LP, respectively, with respect to the total supplied liquid flow rate $m_{\mathrm{L}}$ for the case in which a fluid amplifier system is incorporated into the atomizer. As mentioned in section 2.3, the offsets of the fluid amplifier system are fixed to be $-0.5 \mathrm{~mm}$ and $0.6 \mathrm{~mm}$ for the first-stage and the secondstage, respectively.

Both $m_{\mathrm{Ls}}$ and $m_{\mathrm{Ll}}$ increase monotonically as $m_{\mathrm{L}}$ increases. However, the rate of increase for $m_{\mathrm{Ls}}$ is greater than that for $m_{\mathrm{Ll}}$. In other words, if $m_{\mathrm{L}}$ is small, then $m_{\mathrm{Ll}}$ is larger than $m_{\mathrm{Ls}}$. However, if $m_{\mathrm{L}}$ increases and exceeds approximately $7 \mathrm{~g} / \mathrm{s}$, then the value of $m_{\mathrm{Ls}}$ exceeds $m_{\mathrm{Ll}}$. Corresponding to the flow rate characteristics, the total Sauter mean diameter $\left(S M D_{\mathrm{t}}: \triangle\right)$ given by Eq. (1) is constant at approximately $70 \mu \mathrm{m}$ over a relatively broad flow rate range. These atomization characteristics are desirable in our study. Therefore, the flow rate characteristics of the fluid amplifier system incorporated into the atomizer are important and will be compared with those of the new fluid amplifier shown in Fig. 5.

3.2 Functions of the main flow and control flow in the fluid amplifier system ${ }^{(6)}-(8)$

Previously we examined the flow rate and spray characteristics for the case in which a fluid amplifier system was incorporated into a Y-jet type airblast atomizer. However, the atomizer has a structure in which the liq- 
uid branches out into a main flow and a control flow from one inlet in the first-stage fluid amplifier. These branched

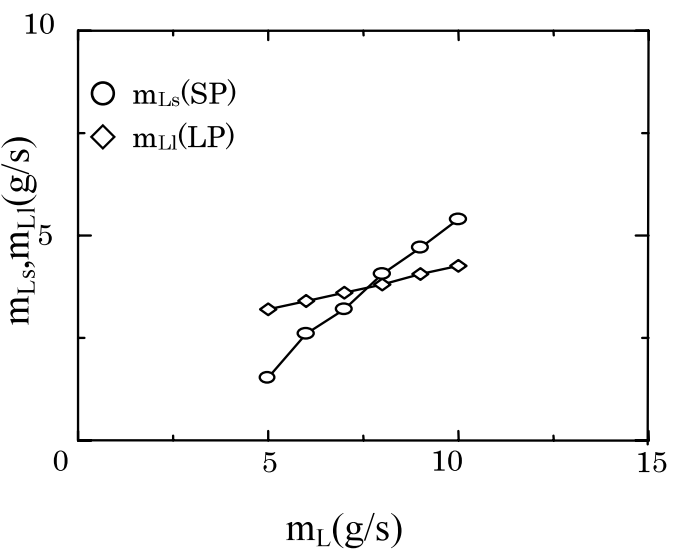

(a) Main flow rate of $1 \mathrm{st}$ fluid amplifier $=3.0 \mathrm{~g} / \mathrm{s}$

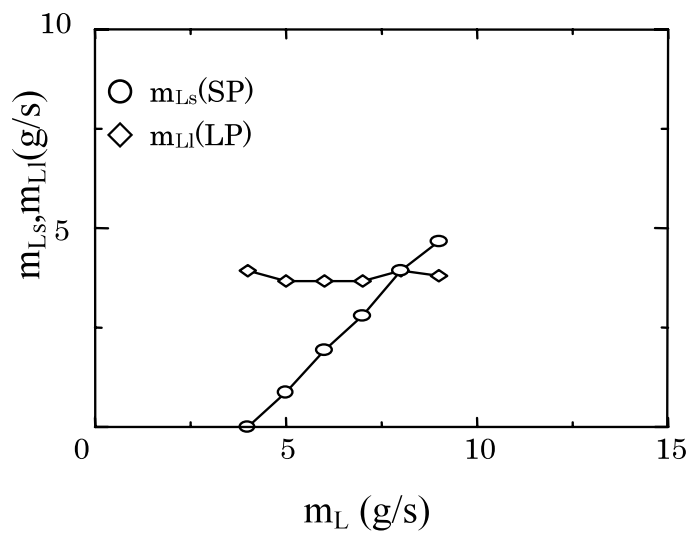

(b) Main flow rate of $1 \mathrm{st}$ fluid amplifier $=4.0 \mathrm{~g} / \mathrm{s}$

Fig. 7 Effects of total liquid flow rate on liquid division (Splitter offset of No. 1: $-0.5 \mathrm{~mm}$, No. 2: $0.6 \mathrm{~mm}$ ) flows cannot be regulated individually. Furthermore, a number of aspects of the flow rate division in the fluid amplifier remain unclear. Therefore, we decided to experimentally investigate the relationship between the flow rate characteristics and the flow in the fluid amplifier itself without incorporating the fluid amplifier into the atomizer. This was achieved by using only the fluid amplifier shown in Fig. 5.

Figure 7 shows the variations of liquid flow rates $m_{\mathrm{Ls}}$ and $m_{\mathrm{Ll}}$ from the SP and the LP (shown in Fig. 5), respectively, with the total flow rate $m_{\mathrm{L}}$ when liquid is supplied from the first-stage main nozzle and the control port, respectively. Figure 7 (a) and (b) illustrate cases in which the main flow rate (the rate of the flow supplied from the main nozzle in Fig. 5) is fixed at $3.0 \mathrm{~g} / \mathrm{s}$ and $4.0 \mathrm{~g} / \mathrm{s}$, respectively, and the flow rate of the control flow (the flow supplied from the control port in Fig. 5) is allowed to vary. Although $m_{\mathrm{Ll}}$ becomes constant when the main flow rate is $4.0 \mathrm{~g} / \mathrm{s}\left(\right.$ Fig. 7 (b)), in either case, $m_{\mathrm{Ll}}$ is greater than $m_{\mathrm{Ls}}$ when $m_{\mathrm{L}}$ is small, and the relationship is reversed when $m_{\mathrm{L}}$ increases (Fig. 7 (a) and (b)). The value of $m_{\mathrm{L}}$ at which the relationship between $m_{\mathrm{L} 1}$ and $m_{\mathrm{Ls}}$ is reversed is approximately $7.5 \mathrm{~g} / \mathrm{s}$ and $8.0 \mathrm{~g} / \mathrm{s}$ for main flow rates $3.0 \mathrm{~g} / \mathrm{s}$ (Fig. 7 (a)) and $4.0 \mathrm{~g} / \mathrm{s}$ (Fig. 7 (b)), respectively. The result shown in Fig. 7 (a) is quite similar to the case in which a fluid amplifier system is incorporated into the atomizer (Fig. 6).

It is surmised that the agreement between these flow rate characteristics shown in Fig. 7 (a) and the flow rate characteristics shown in Fig. 6 also applies to the flow rate division between the main flow and the control flow at the first stage when a fluid amplifier system is incorporated into the atomizer.

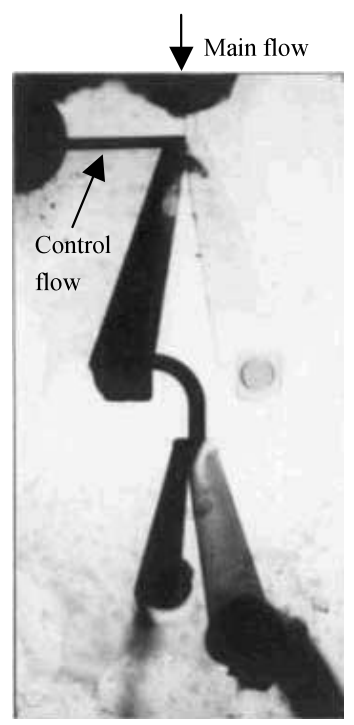

(a) Control flow rate of 1 st fluid amplifier $=2.0 \mathrm{~g} / \mathrm{s}$

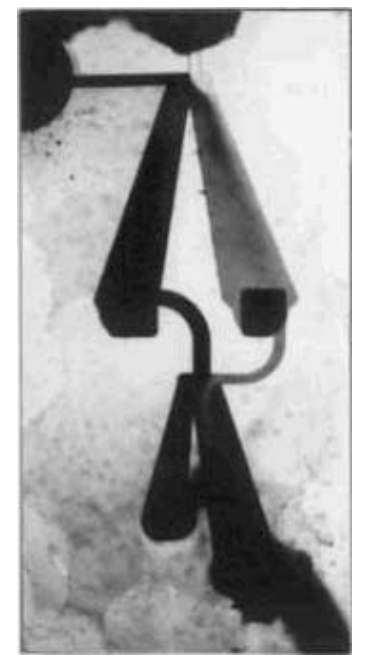

(b) $3.5 \mathrm{~g} / \mathrm{s}$

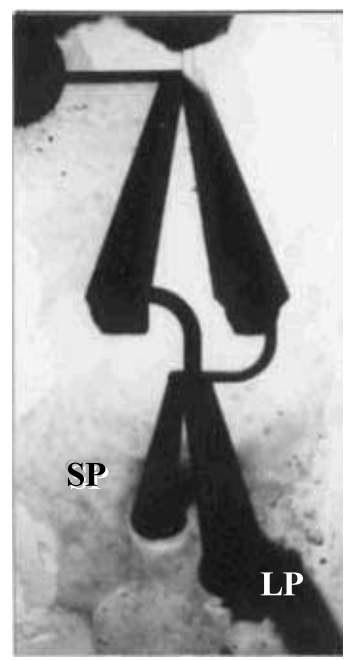

(c) $5.0 \mathrm{~g} / \mathrm{s}$

Fig. 8 Photographs of internal flow in fluid amplifiers with no atomizing air (Splitter offset of No. 1: $-0.5 \mathrm{~mm}$, No. 2: $0.6 \mathrm{~mm}$, Main flow rate $=4.0 \mathrm{~g} / \mathrm{s}$ ) 


\subsection{Flow visualization of the liquid inside a fluid amplifier system $^{(7),(8)}$}

Figure 8 shows the flow visualization results for the effect of the control flow rate on the flow rate characteristics of the fluid amplifier. It should be noted that the flow rate from the first-stage main nozzle is $4.0 \mathrm{~g} / \mathrm{s}$ and that this flow rate corresponds with the case in which favorable flow rate characteristics (Fig. 7 (a)) were obtained.

When the first-stage control flow (the black liquid) increases from $3.5 \mathrm{~g} / \mathrm{s}$ (Fig. 8 (b)) to $5.0 \mathrm{~g} / \mathrm{s}$ (Fig. 8 (c)), the liquid that flowed in the first-stage main flow path (the right flow path) is evidently increased compared to the $2.0 \mathrm{~g} / \mathrm{s} \mathrm{control} \mathrm{flow} \mathrm{(Fig.} 8$ (a)). This is due to the influx of the control flow into the main flow, resulting in an increase in the flow rate of the control flow in the second-stage amplifier. The increase in the flow rate of the control flow in the second stage means an increase in the amount of influx into the second-stage main flow path (the left flow path), which causes most of the liquid to flow into the SP.

When the flow rate of the first-stage control flow is low $(2.0 \mathrm{~g} / \mathrm{s} ;$ Fig. 8 (a)), the control flow does not enter the first-stage main flow path (the right flow path). Therefore, even though the flow rate of the second-stage control-flow is small, the fact that most of the control flow at the entrance of the second-stage amplifier enters the control flow path (the right flow path) is revealed by the white streamline continuing from the main flow path of the first-stage control flow. Therefore, when the total supplied flow rate $m_{\mathrm{L}}$ is low, relatively more liquid flows into the LP, resulting in a flow rate characteristic wherein the relationship between $m_{\mathrm{Ll}}$ and $m_{\mathrm{Ls}}$ is reversed as $m_{\mathrm{L}}$ increases.

\section{Atomization Characteristics of the Y-Jet Type Air- blast Atomizer}

\subsection{Flow rate characteristics of the fluid amplifier system}

Figure 9 (a), (b), and (c) show the variation of the flow rates $m_{\mathrm{Ls}}$ and $m_{\mathrm{Ll}}$ with the liquid flow rate $m_{\mathrm{Ls}}$ for the atomization air flow rates of 4.0,6.0, and $8.0 \mathrm{~g} / \mathrm{s}$. At any air flow rate, both $m_{\mathrm{Ls}}$ and $m_{\mathrm{Ll}}$ increase monotonically as $m_{\mathrm{L}}$ increases. The rate of increase is higher for $m_{\mathrm{Ls}}$, indicating a characteristic that should suppress the mean diameter for the entire spray, even when a large flow rate is involved. Furthermore, the value of $m_{\mathrm{L}}$ at which the magnitude relationship between $m_{\mathrm{Ls}}$ and $m_{\mathrm{Ll}}$ is reversed, with the exception of the case in which $m_{\mathrm{A}}=8.0 \mathrm{~g} / \mathrm{s}$, is approximately $7 \mathrm{~g} / \mathrm{s}$, which indicates favorable flow rate characteristics over a broad liquid flow rate range. In a previous paper, we reported only the case involving an air flow rate of $6.0 \mathrm{~g} / \mathrm{s}$, a rate at which the magnitude relationship between $m_{\mathrm{Ls}}$ and $m_{\mathrm{Ll}}$ is reversed, we confirmed that a configuration combining a first-stage offset of $-0.5 \mathrm{~mm}$, a second-stage offset of $0.6 \mathrm{~mm}$, and a third-stage orifice diameter of $1.0 \mathrm{~mm}$, produces favorable flow rate charac-

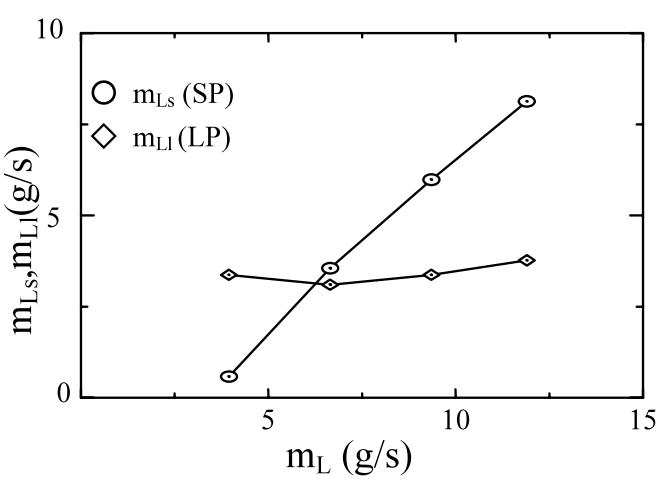

(a) $m_{\mathrm{A}}=4.0 \mathrm{~g} / \mathrm{s}$

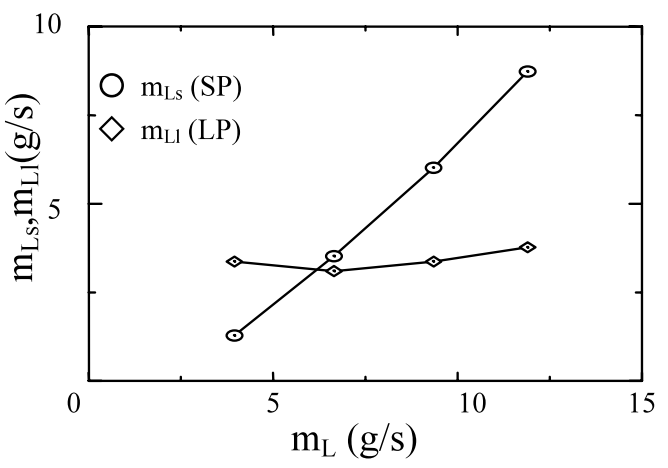

(b) $m_{\mathrm{A}}=6.0 \mathrm{~g} / \mathrm{s}$

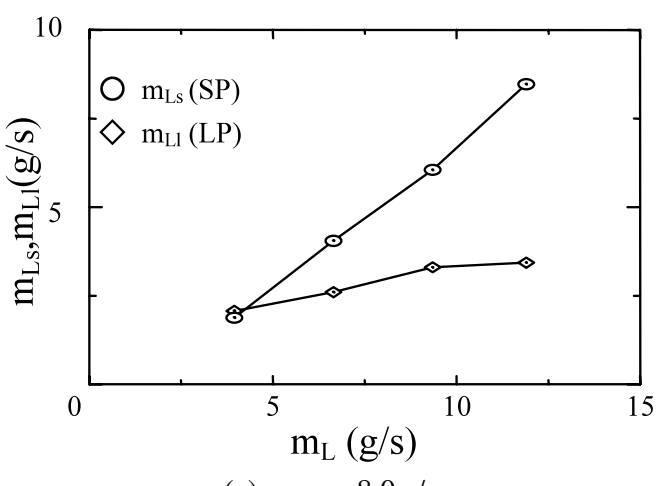

(c) $m_{\mathrm{A}}=8.0 \mathrm{~g} / \mathrm{s}$

Fig. 9 The variation of liquid division with total liquid flow rate (Splitter offset of No. 1: $-0.5 \mathrm{~mm}$, No. 2: $0.6 \mathrm{~mm}$ )

teristics, even when the air flow rate varies.

\subsection{Mean diameter}

Figure 10 shows the measured values of the $S M D$ $\left(S M D_{\mathrm{s}}: \bigcirc ; S M D_{1}: \diamond\right)$ of the spray ejected from the SP and the LP, respectively, and the variations of the total $S M D_{\mathrm{t}}$ $(\triangle)$ for the overall spray with the supplied liquid flow rate $m_{\mathrm{L}}$. Figure 10 (a), (b), and (c) correspond to Fig. 9 (a), (b), and (c), which show the flow rate characteristics of the fluid amplifier.

Figure 10 (a) illustrates the case in which the air flow rate $m_{\mathrm{A}}=4.0 \mathrm{~g} / \mathrm{s}$. It is found that as $m_{\mathrm{L}}$ increases, the $S M D_{\mathrm{s}}$ and the $S M D_{1}$ increase, whereas the $S M D_{\mathrm{t}}$ for the total spray remains fixed at approximately $70 \mu \mathrm{m}$. Figure 10 (b) and (c) show cases in which the air flow rates are $m_{\mathrm{A}}=6.0 \mathrm{~g} / \mathrm{s}$ and $m_{\mathrm{A}}=8.0 \mathrm{~g} / \mathrm{s}$, respectively. As the atom- 


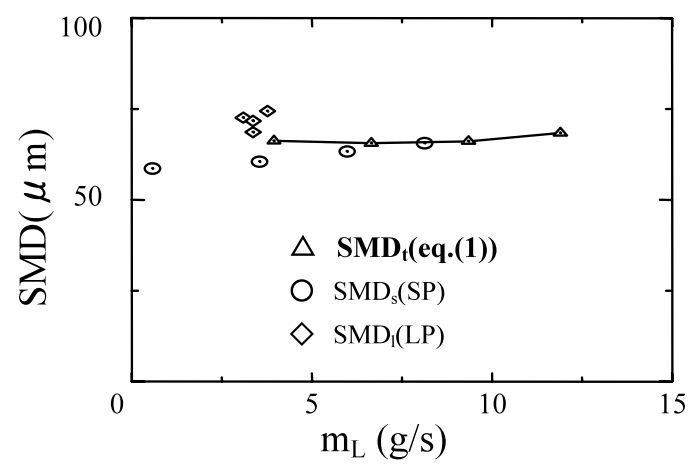

(a) $m_{\mathrm{A}}=4.0 \mathrm{~g} / \mathrm{s}$

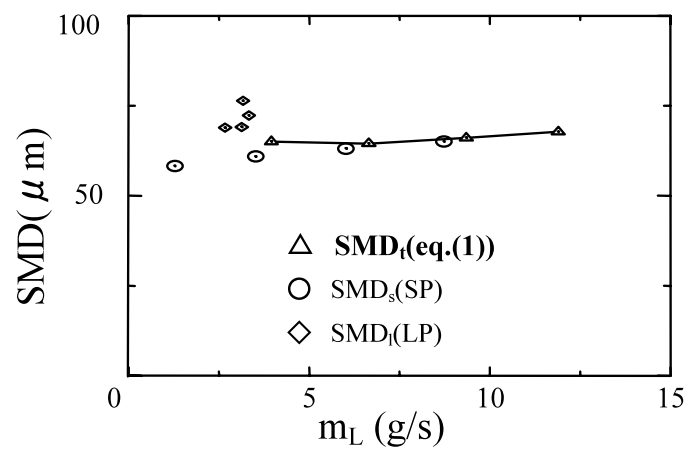

(b) $m_{\mathrm{A}}=6.0 \mathrm{~g} / \mathrm{s}$

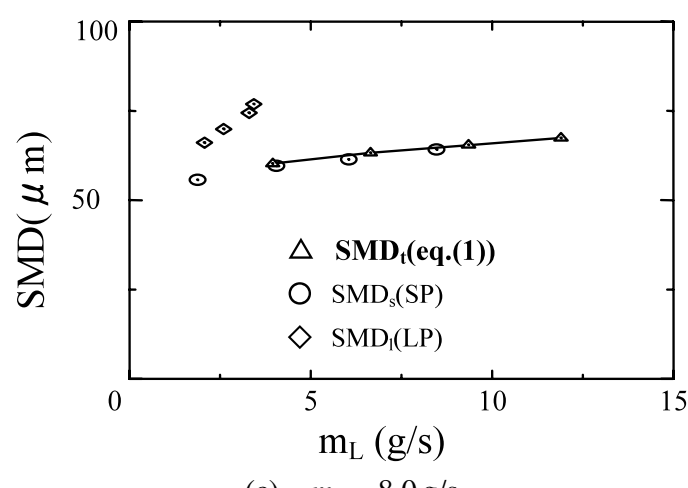

(c) $m_{\mathrm{A}}=8.0 \mathrm{~g} / \mathrm{s}$

Fig. 10 The variation of $S M D_{\mathrm{t}}$ with total liquid flow rate (Splitter offset of No. 1: $-0.5 \mathrm{~mm}$, No. 2: $0.6 \mathrm{~mm}$ )

izing air flow rate increases from $m_{\mathrm{A}}=4.0 \mathrm{~g} / \mathrm{s}$ (Fig. 10 (a)) to $6.0 \mathrm{~g} / \mathrm{s}$ and then to $8.0 \mathrm{~g} / \mathrm{s}$, the $S M D_{\mathrm{t}}$ decreases slightly. However, whereas for $m_{\mathrm{A}}=4.0 \mathrm{~g} / \mathrm{s}$ and $6.0 \mathrm{~g} / \mathrm{s}$, the $S M D_{\mathrm{t}}$ remains virtually constant, independent of $m_{\mathrm{L}}$, at $m_{\mathrm{A}}=$ $8.0 \mathrm{~g} / \mathrm{s}$, a tendency appears whereby the $S M D_{\mathrm{t}}$ also increases as the flow rate $m_{\mathrm{L}}$ increases. The reason for this phenomenon may be due to the fact that, as described in the flow rate characteristics (Fig. 9(c)), when $m_{\mathrm{L}}$ is small, the flow rates of the SP $\left(m_{\mathrm{Ls}}\right)$ and the LP $\left(m_{\mathrm{Ll}}\right)$ are virtually equal, and no characteristic is produced that clearly reverses the relationship between $m_{\mathrm{Ls}}$ and $m_{\mathrm{Ll}}$.

In a previous paper ${ }^{(3)}$, we reported a number of cases in which the liquid had a tendency to adhere to the inner port surface in the SP, the LP, or both, when the air flow rate had a value other than $m_{\mathrm{A}}=6.0 \mathrm{~g} / \mathrm{s}$, e.g., $m_{\mathrm{A}}=4.0 \mathrm{~g} / \mathrm{s}$ or $8.0 \mathrm{~g} / \mathrm{s}$, for which the liquid was ejected in a film state,

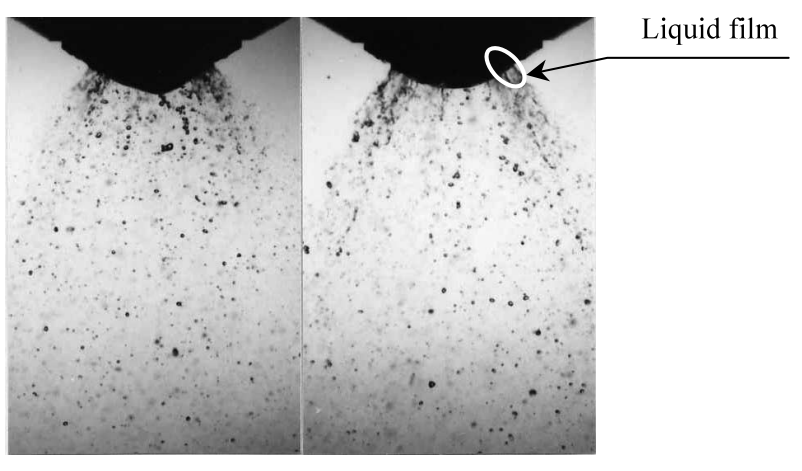

$$
m_{\mathrm{L}}=6.65 \mathrm{~g} / \mathrm{s} \quad 11.9 \mathrm{~g} / \mathrm{s}
$$

(a) $m_{\mathrm{A}}=4.0 \mathrm{~g} / \mathrm{s}$

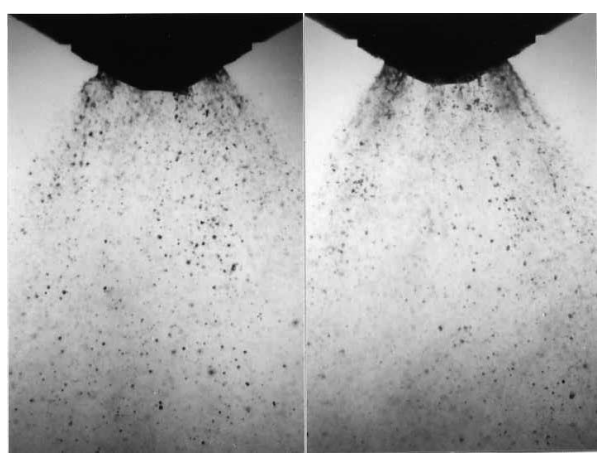

$$
m_{\mathrm{L}}=6.65 \mathrm{~g} / \mathrm{s} \quad 11.9 \mathrm{~g} / \mathrm{s}
$$

(b) $m_{\mathrm{A}}=6.0 \mathrm{~g} / \mathrm{s}$

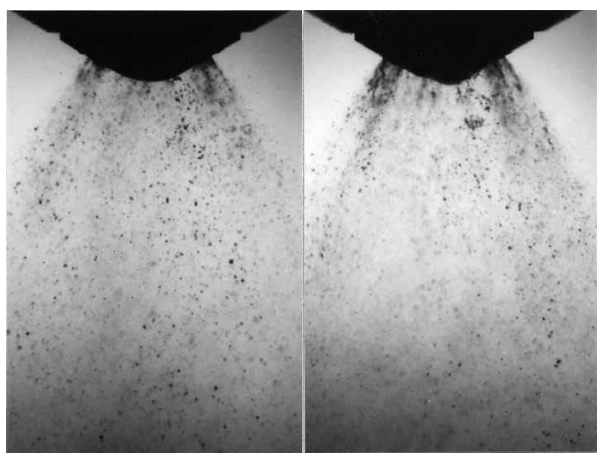

$$
m_{\mathrm{L}}=6.65 \mathrm{~g} / \mathrm{s} \quad 11.9 \mathrm{~g} / \mathrm{s}
$$

(c) $m_{\mathrm{A}}=8.0 \mathrm{~g} / \mathrm{s}$

Fig. 11 Spray pattern of Y-jet atomizer (Splitter offset of No. 1: $-0.5 \mathrm{~mm}$, No. 2: $0.6 \mathrm{~mm}$ )

which caused the deterioration of atomization. However, we previously examined the influence of the LP dimensions ${ }^{(3)}$ and the fluid amplifier offset ${ }^{(4),(5)}$ on the atomization characteristics, and the result obtained in the present study shows a significant improvement in the atomization characteristics.

\subsection{Pattern of atomization}

Figure $11(a)$, (b) and (c) show photographs of changes in the atomization pattern as a function of the liquid flow rate $m_{\mathrm{L}}$ using air flow rates of $m_{\mathrm{A}}=4.0,6.0$, and $8.0 \mathrm{~g} / \mathrm{s}$. In the case of $m_{\mathrm{A}}=4.0 \mathrm{~g} / \mathrm{s}$, the low atomizing air flow rate produces coarse droplets at any liquid 
flow rate. However, because an appropriate flow rate division is achieved in the fluid amplifier system, little change is observed in the pattern of atomization, even when the liquid flow rate increases from $6.65 \mathrm{~g} / \mathrm{s}$ to $11.9 \mathrm{~g} / \mathrm{s}$, which holds the $S M D_{\mathrm{t}}$ value for the entire spray constant. In addition, in the case of $m_{\mathrm{A}}=6.0 \mathrm{~g} / \mathrm{s}$, there is little formation of liquid film at the nozzle outlet despite an increase in the liquid flow rate. Moreover, even if some film is formed, this film becomes favorably atomized by the air flow.

As shown in Fig. 9(a) and (b), the value of $m_{\mathrm{L}}$ at which the magnitude relationship between the liquid flow rates of the SP and LP is reversed is $7 \mathrm{~g} / \mathrm{s}$, which is an appropriate flow rate characteristic, for both $m_{\mathrm{A}}=4.0 \mathrm{~g} / \mathrm{s}$ and $m_{\mathrm{A}}=6.0 \mathrm{~g} / \mathrm{s}$, ensuring that the $S M D_{\mathrm{t}}$ value for the entire spray is regulated to a constant value.

In contrast, for the case of $m_{\mathrm{A}}=8.0 \mathrm{~g} / \mathrm{s}$, the value of $m_{\mathrm{L}}$ at which the magnitude relationship between the flow rates of the SP and LP is reversed is extremely low $(4.0 \mathrm{~g} / \mathrm{s})$, as shown in Fig. 9 (c). Therefore, the flow rate of the SP is relatively large. This causes the formation of a liquid film at the SP, with a confirmed tendency for the production of coarse droplets.

In this case, a tendency exists wherein the total mean diameter $S M D_{\mathrm{t}}$ increases as the liquid flow rate increases; however, liquid breakup is promoted due to the fact that the atomizing air flow rate is large, thus the rate of increase of the $S M D_{\mathrm{t}}$ is suppressed (Fig. $10(\mathrm{c})$ )).

\section{Conclusions}

In the present paper, with the objective of improving the atomization characteristics that produce a fixed mean diameter in a manner independent of the liquid flow rate, we focused on the characteristics of a fluid amplifier system, which plays a critical role in the determination of liquid flow rate division and examined the relationship between the fluid amplifier characteristics and the atomization characteristics. The following results were obtained:

(1) An appropriate combination of fluid amplifier offsets produces an appropriate division of liquid flow rates to atomizer ports, which should result in favorable atomization characteristics.

(2) In the measurement of the flow rate characteristics of a fluid amplifier not incorporated into the atomizer, we verified the flow rate division between the main flow and the control flow in the first-stage amplifier for conditions that exhibit favorable flow rate characteristics.

(3) By visualization of the flow inside a fluid am- plifier, we studied the relationship between the flow rate characteristics and the variations in the first- and secondstage flow rate divisions.

(4) Within the scope of experiments conducted in this study, we confirmed that even with a change in air flow rate, the characteristic that regulates the total $S M D_{\mathrm{t}}$ value for the overall spray can be maintained constant.

\section{References}

( 1 ) Ozaki, S. and Hara, Y., Fluidics, (in Japanese), (1967), pp.45-52, Nikkan-Kougyou Shinbunsya.

(2) Inamura, T. and Nagai, N., Control of Mean Droplet Diameter Issued from Y-Jet-Type Airblast Atomizer by Using Fluid Amplifier, Atomization and Sprays, Vol.5, No.3 (1995), pp.243-260.

( 3 ) Daikoku, M., Tanno, S. and Inamura, T., Spray Characteristics of Y-Jet-Type Atomizer Embedding Fluid Amplifier, Proceedings of the Seventh International Conference on Liquid Atomization and Spray Systems (ICLASS'97), (1997), pp.318-325.

( 4 ) Daikoku, M., Sakai, H., Furudate, H., Kaga, T., Inamura, T. and Tanno, S., Spray Characteristics of Y-Jet-Type Atomizer Embedding Fluid Amplifier, Atomization, (in Japanese), Vol.8, No.24 (1999), pp.180189.

( 5 ) Daikoku, M., Sakai, H., Furudate, H., Kaga, T. and Inamura, T., Characteristics of Y-Jet-Type Airblast Atomizer with Self-Control Function, Proceedings of the Seventh Symposium (ILASS-Japan) on Atomization, (in Japanese), (1998), pp.173-178.

( 6 ) Daikoku, M., Sakai, H., Furudate, H., Kaga, T., Inamura, T. and Tanno, S., Study on the Improvement in Characteristics of Y-Jet-Type Airblast Atomizer with Self-Control Function (The Effects of the Fluid Amplifier on the Spray Characteristics), Proceedings of JSME Yonezawa Division Meeting, (No.991-2), (in Japanese), (1999), pp.149-150.

( 7 ) Daikoku, M., Sakai, H., Furudate, H., Kaga, T., Inamura, T. and Tanno, S., Characteristics of Y-JetType Airblast Atomizer with Self-Control Function (2nd Report: the Effects of the Fluid Amplifier Dimensions on the Spray Characteristics), Proceedings of the Eighth Symposium (ILASS-Japan) on Atomization, (in Japanese), (1999), pp.271-276.

( 8 ) Daikoku, M., Furudate, H., Sakai, H., Kaga, T., Inamura, T. and Tanno, S., Spray Characteristics of Y-Jet-Type Atomizer Embedding Fluid Amplifier (2nd Report: The Effect of Fluid Amplifier Dimension on Spray Characteristics), Proceedings of the Eighth International Conference on Liquid Atomization and Spray Systems (ICLASS2000), CD-ROM. 